\title{
UNA SOCIEDAD INASIBLE LA INESTABLE CONSTITUCIÓN DE LO SOCIAL EN EL PENSAMIENTO DE CLAUDE LEFORT
}

\author{
An Ungraspable Society \\ The Unstable Constitution of the Social in the Thought of Claude Lefort \\ Germán Pinque \\ Universidad Nacional de Córdoba \\ gpinque@gmail.com
}

\begin{abstract}
Resumen:
En este trabajo desarrollo una serie de conceptos e ideas provenientes de la filosofía política de Claude Lefort para pensar las relaciones de los "hombres" con sus formas y condiciones de existencia políticas. Comenzaré refiriéndome a los rasgos generales de su filosofía, especialmente, la indagación y postulación de lógicas, principios y articulaciones sociales como claves de lectura de los hechos y fenómenos políticos. Luego, avanzaré sobre un conjuntos de conceptos interrelacionándolos como forma de exponer tres ideas centrales en torno a la "inestabilidad" de lo social: primero, la comprensión de la política en tanto proceso decisivo de institución, ordenamiento o unificación de las divisiones ontológicas de la sociedad; en segundo lugar, analizaré la imagen que ofrece Lefort de una sociedad que está operando sobre sí misma mediante su propia voz, aprovechando los "frutos" de las libertades políticas y de la legitimidad del debate sobre lo legítimo y lo ilegítimo que trajo consigo la modernidad; $y$, tercero, abordaré la "aventura" que según el autor se inicia con la proclamación y difusión de los derechos del hombre entendidos como un vector de cambio inestabilidad social. Finalmente, repasaré críticamente el presupuesto de una sociedad en la que opera un antagonismo ontológico y cuya "política" parece devenir casi exclusivamente en una ética de la competencia electoral.
\end{abstract}

\section{Palabras clave:}

Filosofía política, Claude Lefort, democracia, derechos humanos, política.

\begin{abstract}
:
In this work I develop a series of concepts and ideas from Claude Lefort's political philosophy to think about the relationships of "men" with their forms and conditions of political existence. I will begin by referring to the general features of his philosophy, especially the inquiry and postulation
\end{abstract}


of social logic, principles and articulations as keys to reading political events and phenomena. Then, I will advance on a set of concepts interrelated as a way of exposing three central ideas around the "instability" of the social: firstly, the understanding of politics as a decisive process of institution, ordering or unification of the ontological divisions of the society; secondly, I will analyze the image that Lefort offers of a society that is operating on itself through its own voice, taking advantage of the "fruits" of political freedoms and the legitimacy of the debate on the legitimate and the illegitimate that modernity brought with it. ; and, thirdly, I will address the "adventure" that according to the author begins with the proclamation and dissemination of human rights understood as a vector of social instability change. Finally, I will critically review the assumption of a society in which an ontological antagonism operates and whose "politics" seems to become almost exclusively an ethic of electoral competition.

\section{Keywords:}

Political philosophy, Claude Lefort, Democracy, Human Rights, Politics.

Recibido: 30/04/2021

Aceptado: 17/06/2021

\section{El PENSAMIENTO DE CLAuDE LEFORT}

La filosofía política de Lefort conceptualiza principios, divisiones y lógicas de institución y funcionamiento de lo social. No trata de analizar o indagar (al menos en principio) un conjunto de hechos sociales empíricos específicos, tampoco relaciones, ámbitos, mecanismos o reglas políticas particulares -objeto de estudio de la sociología política o de las ciencias políticas, sugiere el autor en diferentes trabajos-, sino más bien pensar las articulaciones y oposiciones que permitan "descifrarlos" (1990: 188). Por ello, el autor pone su trabajo conceptual más allá de cualquier investigación o exigencia objetivista, positiva, y se enfoca fundamentalmente en la interpretación de obras, momentos y procesos históricamente decisivos, fundadores. En este sentido, uno de los focos de la obra de Lefort son las "mutaciones" históricas, ideológicas, políticas, etc., ya que ellas (tanto si tienen lugar de manera lenta y silenciosa o rápida y estruendosa), suponen y revelan de manera ejemplar aquellos principios o lógicas de institución de lo social y sus cambios.

La obra de Lefort intenta traer a la conciencia y al conocimiento, por todo ello, las condiciones y los cambios de condiciones en que se producen los fundamentos y significados de lo social o, más bien, la ausencia de fundamentos y significados trascendentes, como veremos más adelante en relación con la modernidad y la democracia. Más aún, Lefort, en consonancia con el espíritu mismo de la modernidad, desengaña acerca de algún fundamento estable o trascendente de lo social y releva que, en definitiva, este depende de la autoinstitución y autoorganización específicamente política de la sociedad, negando cualquier papel decisivo a otro agente o base, sea económica, antropológica, sociológica, etc. (Moyn, 2013: 57). 
Por todo esto, el pensamiento de Lefort alumbra nuestra inscripción o implicación en estructuras simbólicas de las cuales deviene -y depende- la inteligibilidad de la realidad social, la unidad, representación y configuración misma de la sociedad o el surgimiento de -indispensables- lugares de poder desde los que encausar y controlar su curso. En este sentido, ofrece, además, una reconstrucción global de nuestra situación en el mundo social y del contexto significativo de nuestras acciones, una reconstrucción que postula a la política $-\mathrm{O}$ a lo político inaugurado con la modernidad- como una dimensión constitutiva de la realidad social.

El trabajo del autor contribuye y adquiere un valor especial para el pensamiento político e incluso social, en tanto pone en cuestión creencias -e ilusiones dogmáticassobre los fundamentos de la sociedad, Ilama la atención sobre los significados, lógicas y principios detrás de los hechos y fenómenos empíricos y ayuda a pensar las condiciones que favorecen -o no- la libertad y la democracia. La obra de Lefort revela así, en las grandes genealogías que traza, en el sistema que construye, una referencia y un punto de vista para examinar narrativas y discursos acerca de las lógicas de lo social; ofrece además una suerte de esquema narrativo o drama de cómo son las cosas para las sociedades, qué conflictos y deseos las anima, qué actores participan, en qué escenarios.

\section{LO SOCIAL, LO POLÍTICO Y LAS DIVISIONES ANTAGÓNICAS}

"Lo social" es en Lefort es un producto -político- extraño, un resultado paradójico del entrelazamiento y funcionamiento de dos órdenes: por una parte, un conjunto de fuerzas y deseos divergentes, de divisiones antagónicas de carácter ontológico, que se constituyen y operan como principios y factores condicionantes para la creación y existencia misma significados, relaciones o identidades: el orden simbólico; y, por otra parte, un conjunto de significados sustanciales, históricos, situados, ideológicos, desplegados para dar satisfacción a un profundo anhelo -iantropológico?- de representación, unificación social y resolución de aquellas divisiones sociales de carácter ontológico: el orden imaginario. De este entrelazamiento surge lo social y en él se juegan las condiciones de posibilidad mismas de la coexistencia social y del sentido, coherencia o valoración de esa coexistencia social (Marchart, 2009: 136138).

En este marco, los individuos y las sociedades cobran existencia, unidad y se orientan, sitúan, posicionan uno/as de otro/as, sobre el trasfondo de un antagonismo y una conflictividad irreductible, irresoluble, constitutiva, y a partir de marcos sociosimbólicos elaborados discursivamente que intentan cerrar u ocultar una y otra vez esas divisiones. Esta unidad es, puede agregarse, tendencial, proyectiva, inestable, constituida por múltiples relaciones imprevistas, temporales; nunca algo sólido o un estado definido. Como describe Stavrakakis, retomando el pensamiento de Lefort acerca de la democracia:

no existe una unidad orgánica esencial que pueda definir a la sociedad de una vez y para siempre. Esto también lo demuestra la relatividad histórica, cultural, de diferentes formas de unidad social, las diferentes formas (construcciones) de la sociedad. En consecuencia, ningún análisis (...) puede partir de la identificación de un punto de referencia esencialista 
privilegiado (un ideal que garantizaría la unidad) para implantarlo en el corazón de la sociedad con el fin de resolver su ambigüedad (2007: 178).

No existe unidad, ni puntos de referencia ni delimitaciones esenciales, fijas; pero cuando lo social, en el marco de aquel "entrelazamiento", consigue unidad, sentido, identidad, consistencia, continuidad o logra ser espacio de orquestación y de reconocimiento común, es gracias a la política y a su eficacia simbólica: es la política la que produce a la sociedad -no la economía, por ejemplo. Como dice Marchart "todo ser social es puesto en escena, adquiere significado y cobra forma políticamente" (2009: 146).

La política, en este sentido, remite a procesos decisivos de institución, ordenamiento o unificación de la sociedad y de sus divisiones; es, simultáneamente, un conjunto de modalidades o formas (despotismo, democracia, totalitarismo, etc.) en que se articula y se vuelve inteligible la sociedad; y remite también a un conjunto de distinciones y lógicas que hacen funcionar lo social: qué es lo verdadero o lo falso, lo justo de lo injusto, lo legitimo de lo ilegítimo, que establecen además los límites de lo pensable. En síntesis, estas distinciones fundamentales y constitutivas permiten leer, ver o nombrar a la sociedad o, en otras palabras, gracias a estas distinciones el mundo social y nuestra posición en él adquiere sentido.

Así, es en virtud de esta dimensión política, simbólica -y particularmente de un dominio político específico, la ideología- donde se consuma, provisoriamente, la unidad imaginaria de la sociedad; es mediante la política que se reduce y morigera la división, el antagonismo de lo social, su conflictividad irreductible pero paradójicamente constitutiva (Flynn, 2005: 207). De esta manera, lo político permite a la sociedad, según Lefort, deslindar su interior y su exterior, su adentro y su afuera y le permite también autopresentarse y representarse a sí misma. Lo político cumple este papel en tanto ejercicio de un poder elevado de la sociedad: supone un poder externo a la misma y a sus divisiones. De hecho, no habría, en el pensamiento de Lefort -en contra de Marx- una sociedad liberada de esta división o liberada de esta lógica de funcionamiento y constitución a través del poder y del discurso desde una cierta externalidad.

Por todo ello, estas divisiones sociales -entre Estado y sociedad civil, entre clases, entre sectores de actividad, enumera Lefort (2004: 14)- remiten a un proceso originario, incesante, iterativo. El individuo, la sociedad, no descansan en ninguna sustancia o unidad positiva, son ese proceso o relación o lazo social que se vivirá y experimentará de manera inevitablemente conflictiva, antagónica (Marchart, 2009: 136). Lo social resurge así de diferentes formas y se autotrasciende una y otra vez a partir ese conflicto que está en su base o, desde la perspectiva de Maquiavelo retomada por Lefort, a partir de la división entre los que quieren dominar y los que no quieren ser dominados.

En síntesis, estas divisiones, como una dimensión de los procesos de constitución de lo social, fundan, animan y se entrelazan y se realinean con procesos imaginarios de constitución de lo social. Estos últimos consisten en discursos -ideológicos- que buscan resolver u ocultar el antagonismo, el conflicto, intentan homogeneizar el espacio social o disimular o impulsar los acontecimientos irreversibles que lo 
sacuden. Así, este orden imaginario sutura, reconcilia, deniega aquellas divisiones, pero está destinado a ser permanente alterado, transformado, perturbado...

En definitiva, lo político -en la estela abierta por el pensamiento de Lefort- son estas circunstancias y nombra las dinámicas simbólicas mediante las cuales se genera, da forma, orden, identidad, sentido y permanencia a lo social; pero lo político es también y contradictoriamente, la apertura de un escenario de impugnaciones, inestabilidades, conflictos, mediaciones o cuestionamientos de lo social. Lo político es una instancia -que no se circunscriben a una actividad o espacio determinado- de cualquier espacio o actividad. Bajo ciertos aspectos, está en la naturaleza de esta dimensión ser algo determinante y omnipresente en la constitución de lo social, aunque también cabe pensar que es algo que puede ser debilitado, desvalorizado, clausurado o negado -como ha ocurrido en las dictaduras militares argentinas (Gómez, 1986)-, pero también, de la misma forma, que es algo que inevitablemente, tarde o temprano, resurgirá y reaparecerá, permeando, politizando a la sociedad, a sus instituciones, a sus actores, a sus leyes, a sus prácticas, etc. Lo político es, en fin, un proceso de simbolización de la realidad, disputado, incesante, que pone en forma a la sociedad, le da sentido.

\section{LA MODERNIDAD, LA DEMOCRACIA, EL PUEBLO}

¿Qué hacer frente a estas circunstancias? ¿Qué hacer frente a una sociedad ontológicamente dividida, ambigua y siempre inestablemente definida? Aceptarla o, más aún, revalorizarla. Lo social, sus distinciones y figuras básicas, está sujeto inevitablemente a debates, luchas, negociaciones, como nunca antes lo estuvo. De hecho, la modernidad habilita y genera nuevas condiciones simbólicas para un pensamiento que cuestiona y problematiza lo social. No solo eso, el intento de eliminar, negar o forzar estas condiciones y el proceso simbólico desatado, que prácticamente equivale al "dispositivo democrático" en el pensamiento de Lefort, reconduce a lo social, más específicamente, a la forma política de la sociedad, hacia lo que el autor denomina totalitarismo: un fenómeno propiamente moderno consistente en el deseo de anular el conflicto, encarnar la unidad, absolutizar los límites o distinciones básicas (lo interior del exterior, lo correcto del o incorrecto, lo justo de lo injusto, etc.), sacralizar relatos, agentes, lugares, etc., u ofrecer certezas y fundamentos taxativos, -imposiblemente- incuestionables, definitivos o sólidos (Lefort, 2004: 247; 1990: 78).

En definitiva, para Lefort, debe aceptarse una dinámica irreversible que fue abierta por la modernidad, más específicamente por la Revolución Francesa. Esta supuso una mutación decisiva, preñada de consecuencias, determinante del curso posterior de la historia, que tanto permitió descubrir e incluso obligó a "interpretar lo político" (1988: 94) como puso entre sus decursos sociales y políticos posibles al totalitarismo. Para el autor, esta es una mutación decisiva, una mutación del orden simbólico, una mutación de la forma en la que la sociedad representa su unidad, su identidad, su continuidad (2004: 252-257). No es una transferencia de poder a nuevos actores o grupos, un nuevo diseño institucional o el dominio de una nueva clase social-como algunos han interpretado según Flynn (2006: 133)-; es decir, es un cambio profundo, pero a pesar de ello, según el autor, contiene una continuidad fundamental: 
permanece el lugar del poder constituido durante el Absolutismo. La modernidad, la democracia, tienen así una suerte de deuda con el Absolutismo: este niveló y homogeneizó el campo social (Lefort citado por Flynn, 2005: 166) y constituyó ese lugar-aunque en el marco de otro orden y de otra estructura simbólica de la sociedad, bajo otros estatutos

Según Lefort, la modernidad es consustancial a la falta de certezas, al sentimiento de "enigma" acerca de lo que funda a la sociedad (1990: 141), a la vivencia de esta como algo inacabado, a hacerse, a lograrse continuamente, y, más importante aún, es consustancial a lo político. De hecho, como sostiene Flynn, "para Lefort existe una conexión definida entre el concepto de modernidad y la noción de discurso político. El discurso político y su 'objeto', lo político (le politique), aparecen solo en, y quizás son constitutivos de, la modernidad" (2005: 83). Junto con la modernidad, en definitiva, surge la política y la democracia, definida como una nueva forma de vida, de experimentar el mundo social, una nueva manera de comprendernos a nosotros mismos y de comprender nuestra situación en el mundo. La modernidad supone un proceso continuo de desenvoltura del "dispositivo democrático" y, como decíamos, la permanencia, pero, simultáneamente -un hecho trascendental- el vaciamiento del lugar de poder.

Con la modernidad, el lugar del poder se mantiene, pero cambian sus "estatutos": este lugar será ocupado ahora mediante la competencia electoral, por ejemplo. Esto significa la articulación de instituciones (in)estables que regulan el acceso al poder, pero también, la dependencia de todo el sistema de ideas como la de legitimidad o de soberanía popular. Esta cosmovisión moderna, como podría llamarse, guarda en su seno un problema central para el cual, según Charles Taylor, la Revolución Francesa no pudo producir una solución (2006: 165), un problema que Lefort desarrolla: por una parte, la figura que ocupe el lugar del poder nunca podrá gozar de la autoridad o la legitimidad de la que gozaba el rey, por el contrario, estará siempre sometida a la legitimidad que proviene de una sociedad dividida, conflictiva, cuestionadora.

Por otro lado, la soberanía popular, el pueblo, difícilmente puede manifestarse o representarse como tal. La soberanía del pueblo entendido este como una unidad que expresa una voluntad, es una ilusión: "depende de un discurso político y de una elaboración sociológica e histórica siempre ligada al debate ideológico" (Lefort, 2004: 49). A lo sumo, el pueblo puede ser representado mediante su conversión en ciudadanos, en "unidades contables", al momento del sufragio, como dice Lefort (1990: 191). Pero, por otro lado, el autor parece decir que el pueblo tiene una realidad efectiva, puede efectivamente manifestar su voluntad, expresarse: Lefort presenta al pueblo como una entidad sumamente susceptible y sensible a cualquier forma de dominación y opresión, está en su naturaleza el deseo de ser libre de ellas y de resistir, rechazar, negar; de esa manera, es capaz de surtir efectos diversos. Como sostiene el autor, "la democracia inaugura la experiencia de una sociedad inasible, indomable" (2004: 254) y -puede pensarse- el pueblo está destinado a provocar cambios en modos y direcciones diversas: forzando negociaciones o alianzas para ampliar sus derechos, incitando a la represión del Estado, estimulando contradicciones, enfrentamientos sociales, crisis de legitimidad, etc. 
La democracia, nacida de la modernidad, es así el reconocimiento y establecimiento de reglas institucionales para ocupar el lugar del poder estructuralmente vacío, pero es también una forma social donde se produce dos fenómenos fundamentales: la diferenciación de los discursos que articulan o simbolizan lo real, particularmente, el deslinde del poder político, la ley y el saber antes concentrados en el cuerpo del rey (1990: 23) y el deslinde o división del Estado y la sociedad civil: esta pasa a ocupar el espacio público e iniciar un interminable debate acerca de lo legítimo e ilegítimo y, en este mismo proceso, declara/proclama los/sus derechos o, más aún: el "derecho a tener derechos" (Arendt). De hecho, según Lefort, la legitimidad de este debate sobre lo legítimo o lo ilegítimo define a la democracia (2004: 155).

A partir de este momento, queda claro, en esta nueva cosmovisión, varios aspectos significativos: la institución de lo social depende ya de la auto-institución autónoma de la sociedad; simultáneamente, se pone de manifiesto la fragmentación y división de la sociedad y la potencial reaparición de estas divisiones originarias, en otros planos, en otros contextos, en otros niveles; asimismo, se advierte el carácter vacío del poder, sus nuevas interrelaciones con la ley y con el saber como esferas discursivas autónomas que buscan, diseñan y desarrollan sus propias normas y principios de legitimación; además, la ocupación del poder así como los fundamentos para su ejercicio, nunca serán estables, permanentes, definitivos: el "dispositivo democrático" consiste, en todo caso, en conocer y aceptar esta falta de fundamento positivo (Marchart, 2009: 140).

Finalmente, el nuevo espíritu que recorre la sociedad civil, el "derecho a tener derechos", pone en cuestión y confronta con derechos y privilegios establecidos; no supone ningún contenido determinado, pero constituye un respaldo general a nuevos contenidos, derechos o reclamos. Este "espíritu" se vuelve principio generativo del dispositivo democrático, pero también, introduce el conflicto como posibilidad latente, constante, estructural. La imagen que ofrece Lefort es la de una sociedad que está operando sobre sí misma mediante su propia voz y aprovechando los "frutos" de las libertades políticas y la legitimidad del debate sobre lo legítimo y lo ilegítimo que trajo consigo la modernidad.

\section{EL ESTADO, LA SOCIEDAD CIVIL, LOS DERECHOS DEL HOMBRE}

Para Lefort, la proclamación y difusión de los derechos del hombre a fines del siglo XVIII inicia una aventura histórica aún inconclusa, vibrante: con este acontecimiento se despliega un nuevo orden simbólico, se funda una nueva forma de autocomprensión social y se desatan fuerzas de transformación poderosas e imprevisibles. Para el autor, no se trata solo de la formalización, institucionalización o reconocimiento -jurídico o político- de aquellos derechos, sino también de la conciencia y gradual interiorización de los mismos por parte de amplios y diversos sectores de la sociedad. A partir de este proceso, sugiere Lefort, la realidad social se experimentará virtualmente incompleta, divergente, discordante, inacabada, injusta; una nueva sensibilidad -latente, aguda- atizará una y otra vez estos sentimientos en el "hombre moderno" y en los diversos espacios de la sociedad civil. 
Esta conciencia de los derechos animará infatigablemente nuevas leyes e instituciones y supondrá una base de inestabilidad, creatividad y dinamismo para las sociedades modernas... es esta conciencia, más allá de cualquier ley o institución, la que hace a la democracia misma, y es especialmente el derecho, por su parte, el "código de reescritura" en que esa conciencia intentará plasmar sus demandas, concentrar sus luchas u oponer resistencias al poder. Por todo esto, la proclamación y difusión de los derechos del hombre constituye un impulso radical, emancipador, trascendente que se alojará en el corazón de la sociedad moderna.

En otros sentidos, estas nuevas condiciones implican potenciales e incontrolables dinámicas de impugnaciones y recusaciones de las legalidades reinantes y de sus símbolos, a las que se opondrán incesantemente nuevas ideas de lo socialmente legítimo, incluso rayanas -en el pensamiento de Lefort- con la insumisión o la desobediencia. De allí que la conciencia de estos derechos acechará permanentemente la continuidad y estabilidad del Estado, incluso la paz y la concordia social. Más aún: para unos abrirá las puertas a la anarquía, a la agitación, a la ruptura, a la fragmentación, a la indeterminación, al nihilismo, a la perdida de sentido... será el reino del conflicto y del debate permanente de opiniones, el reino de la inestabilidad y de la relatividad de todo cimiento, referencia, poder, creencia. Para otros, por el contrario, comienza el desmantelamiento y erosión de prejuicios, arbitrariedades, abusos, privilegios, excesos... el nacimiento mismo de la democracia...

Como se ve, esta forma de conciencia, de autocomprensión social, de sensibilidad, se manifiesta de manera ambivalentemente: tanto deviene en un poder social que interpela, rechaza, resiste, enfrenta los corpus jurídicos y los aparatos burocráticos del Estado, como busca y lucha por objetivar, formalizar, institucionalizar y operacionalizar sus demandas y reivindicaciones en él (aunque estos reclamos y derechos serán irreductibles a su objetivación jurídica, siempre la desbordarán, la superarán). Así, surge una inestabilidad estructural esencial: toda definición del Estado se verá tensionada, perturbada, desafiada, reformulada, aunque, al mismo tiempo, este seguirá siendo interpelado, legitimado y ubicado "encima" de la sociedad, como irremplazable reaseguro y garantía de los derechos y de la cohesión social. Aún más, esta ambivalencia constituye, podría decirse, una de las condiciones necesarias e indispensables para las prácticas e instituciones democráticas y para el mismo Estado: está en su "naturaleza" elevarse, trascender y hasta enmascarar el conflicto y el antagonismo social, pero jamás podrá abolirlo; de hecho, en el pensamiento de Lefort el Estado es resultado de esos conflictos y divisiones.

Pero junto con esta ambivalencia, aparecerá aquella que mencionamos antes: la proclamación y difusión de los derechos del hombre va acompañada del fin del absolutismo y, con ello, de una desidentificación definitiva de la posición de poder con la persona y el cuerpo del rey. En otras palabras, el Estado adopta un carácter "desincorporado", se convierte en un lugar vital e indispensable para el ejercicio del poder, la toma de decisiones colectivas, etc., pero es un lugar vacío, que no le pertenece a nadie, que nadie puede reclamar o está destinado a ocupar. Esta situación se resolverá estableciendo un nuevo mecanismo o procedimiento para ocupar ese lugar, como señalamos antes: la competencia política reglamentada. El discurrir 
político de la sociedad, la constitución de lo social, se juega así con nuevos fundamentos y principios de legitimidad, pero también con nuevas reglas operativas, prácticas, concretas, reconocidas y aceptadas, o no, para cumplir y hacer efectivos esos principios.

Pero la democracia no supone solo el reconocimiento de la división social, la legitimidad del debate para dirimir lo legítimo y lo ilegítimo o el diseño y funcionamiento de mecanismos institucionales para ocupar el lugar de poder, sino también nuevas formas de interdependencia -e interferencia- entre el Estado y el campo social, y nuevas formas de interdependencia entre el poder político y el derecho. En el dispositivo democrático el poder se articula y se hace objeto del discurso jurídico, del examen de su racionalidad por parte de la esfera del derecho o la del saber- que se mantendrá exterior al mismo. Además, el derecho se escinde y desafía cualquier interpretación y representación tradicional del poder y de quien lo ocupa y se articula con nuevas fuentes y principios generativos que se localizan en la sociedad civil, en el campo social. Desde la perspectiva de Lefort, el poder no solo no controla el derecho o sus nuevas fuentes, sino que debe conformarse a ellas para tener legitimidad e incluso para garantizar su propio funcionamiento.

La "aventura" iniciada por la proclamación y difusión de los derechos del hombre como el fin del absolutismo introducen así un vector de cambio e indeterminación hasta nuestros días, capaz de producir fisuras o rupturas con distintos alcances y más o menos definitivas en innumerables prácticas e instituciones sociales. Este proceso establece además las condiciones de posibilidad para la impugnación y el cuestionamiento de lo establecido y reconocido por el Estado como de los estatutos del poder político y, más concretamente, habilita condiciones para la potencial emergencia de focos y fuentes incontroladas, dispersas e inesperadas de reclamos y demandas de lo todavía no incorporado o, más aún, de lo denegado a grupos o categorías determinadas de la población (Lefort, 1990: 45; 2004: 27). Desde esta perspectiva, las protestas y reclamos del pueblo se ligan a la autocomprensión y al sistema de referencia simbólico propio del Estado de derecho: es una conciencia que experimenta los procesos sociales abiertos a la intervención colectiva a través del Estado.

Estamos así frente a la imagen de una sociedad que se conduce a sí misma a través de un sistema social, político o simbólico, que bien podría ser caracterizado, tal como lo hace Giddens, como una "desbocada máquina de enorme poderío a la que, colectivamente como seres humanos, podemos manejar hasta cierto punto, pero que también amenaza con escapar de control" (1997: 132) y puede disolverse en antagonismos y conflictos sociales. Todas circunstancias -siguiendo a Giddens- que van acompañadas del dinamismo de las instituciones modernas y de lo que el autor Ilama "reflexividad generalizada", es decir, la revisión continua de la mayoría de los aspectos de la vida social contemporánea a la luz de nuevas informaciones, problemas o conocimientos.

Así, el ejercicio de la opinión y de la libertad política impulsan el despliegue de nuevos derechos y son su condición. Más aún, es el advenimiento de esta nueva experiencia, de este nuevo orden simbólico, el que hace que aunque la sociedad parezca -o esté- dormida, manipulada, atrapa en el consumismo, etc., 
inevitablemente resurja una y otra vez como una sociedad "atormentada, constantemente en debate (...) en saludable efervescencia" (Lefort, 2018: 178) sobre asuntos inesperados o que solo incumbían antes a la vida privada, por ejemplo. En este marco, el espacio público se vuelve y puede describirse como lo hace Wellmer: un "campo de experimentación de convicciones y argumentos" donde todo puede ser tematizado, donde nada está limitado, excluido o condicionado por reglas formales, y donde los debates iniciados allí no pueden ser concluidos por ninguna decisión o procedimiento formal; de hecho, cualquier decisión puede volver a cuestionarse, una y otra vez, a diferencia de lo que ocurre con las discusiones que tiene lugar en los poderes del Estado (1997: 85).

Así, el Estado debe asegurar su continuidad y estabilidad en esta nueva situación; debe extraer su legitimidad de un espacio político animado por luchas y discursos diversos, fragmentarios, dispersos, dispares, que le exigen que responda, que los reconozca; debe recabar y asegurar su poder en un espacio heterogéneo, de representaciones y despliegue de múltiples y antagónicas voces, un espacio que promueve "la formación incesante de sujetos políticos (movimientos de clase, feminismo, pacifismo, regionalismo, etc.) que, mediante variadas 'formas de acción, representación y legitimidad, politizan la sociedad civil, socializan la sociedad política" y tanto neutralizan las pulsiones autoritarias del poder (Gómez, 1986: 140) como pueden inducirlas o demandarlas, en renovadas versiones de totalitarismo o fascismo.

\section{A MODO DE CONCLUSIÓN}

La imagen que construye Lefort sobre los principios, lógicas y modos de funcionamiento y constitución de lo social es clarividente en múltiples aspectos, así como merecedora de revisiones y desarrollos en tanto pensamiento que sirve para pensar las exigencias del presente. Por una parte, la obra del autor orienta a pensar acerca del requerimiento y diseño de instituciones que acojan a una sociedad inasible, indomable, aun sabiendo que ningún mecanismo democrático formal será nunca suficiente. Asimismo, resalta la experiencia, la instalación y el alumbramiento de formas de autocomprensión social ligadas al paradigma de los derechos humanos y de la democracia, por una parte, y el papel de las luchas, de los antagonismos políticos y de los escenarios o espacios estratégicos donde estos tienen lugar, por la otra; además, es una visión que reconoce y proyecta en la sociedad civil un rol dinamizador relevante, fundamental: ella concentra un potencial transformador decisivo (aunque podríamos dudar de que sea necesariamente democrático o democratizador...).

Pero a la vez, podemos preguntar si las figuras que se alzan en el espacio democrático reclamando sus derechos no se vuelven inciertas, espontáneas, hasta cierto punto incomprensibles, si se ignora los intereses estructurales que las animan, así como de los intercambios de las que surgen. Por otra parte, aunque en el mismo sentido, esa imagen de la sociedad y de la democracia es un tanto extraña: no tiene entre sus condiciones y principios de constitución imperativos de índole económicos, materiales; tampoco estos parecen oponerle límite alguno; tampoco juegan en su configuración los símbolos o las narrativas sustantivas vinculadas a la historia o a las identidades nacionales, a las culturas políticas regionales, que podrían enriquecer y 
permitir comprender dinámicas particulares, o rasgos o dimensiones que están en la "naturaleza" de lo social pero que no necesariamente podrán desarrollarse en todos los contextos.

Asimismo, el trabajo de Lefort presupone una forma social, una unidad, cuyo interior, ontológicamente dividido, antagónicamente constitutivo, es regido por una posición o lugar de poder que no está adentro ni afuera: una "autoexterioridad". Este lugar de poder solo existe gracias a esa división, no podemos deshacernos de ella. Esta es la lógica, la condición insuperable de lo social, es el sistema que no puede ponerse en cuestión. Siguiendo esta lógica, ni siquiera la disolución de una unidad en sus contrarios antagónicos liberará a estas nuevas partes de aquella lógica de constitución mediante nuevas divisiones y un nuevo lugar de poder. Incluso, a la inversa, podemos pensar no en la disolución, sino en la conformación de nuevas "unidades" o formas sociales mediante encuentros, intercambios, reconocimientos, confrontaciones, sometimientos, etc. que se cristalizan y se sedimentan con el tiempo y que en este mismo proceso establecen nuevas divisiones o polarizaciones; incluso podríamos llegar al punto o imagen de la historia mundial o de la "humanidad" como esta forma social.

Junto a ello, puede decirse que la imagen de la sociedad construida por Lefort es en gran medida la del Estado nación y, por ello, incluye limitaciones; por ejemplo, volver invisibles o impensables nuevas experiencias liminales, contingentes, de exclusión, resistencia, desplazamiento de orden transnacional, global. Es en esta escala global, siguiendo a Bhabha (2013: 71-78), donde actualmente se inscriben nuevos sujetos minoritarios, marginales, carentes de derechos, radicalmente separados de toda instancia de justicia institucional o simbólica, que llevan las marcas físicas y psíquicas que las dislocaciones de la globalización dejan. Este horizonte discursivo, imaginario, merece ser desarrollado como necesario marco discursivo de significación para esas identidades contingentes, ya que la formulación y petición de derechos depende, siguiendo incluso la misma lógica lefortiana en relación con Estado Nación, del establecimiento de ese orden simbólico que permita la narración, descripción, significación, reparación, de experiencias de opresión o avasallamiento en virtud de un poder que las reconozca. Esta crítica puede dirigirse incluso a la historia misma del Estado nación, cuyo imaginario también ha escamoteado y restringido oportunidades de participación a muchos grupos e individuos pertenecientes a su "interior".

A la vez, Lefort advierte que en la forma y funcionamiento político de la sociedad pueden actuar principios alternativos a la democracia; que los procesos de constitución de lo social pueden "asentarse" sobre lógicas totalitarias, y que esas lógicas son incluso el producto o resultado no querido de la democracia: una suerte de silencioso deslizamiento, de tentación, de lenta mutación frente a la cual debemos estar plenamente despiertos. Aunque, por otra parte, la lógica democrática tal como la entiende Lefort -que es quizás una forma de asimilación mediante el reconocimiento de derechos a lo "desviado", lo oprimido, lo nuevo, lo excéntrico, que es luego "obligado" a participar en el sostenimiento simbólico de esa unidad, de ese sistema- representa o termina siendo en muchos aspectos una suerte de idealización del derecho, de los poderes institucionalizados: es una experiencia que 
parece conllevar, exigir y limitarse a una ética, una ética que conduce a aceptar las reglas de aquella lógica, o cuanto más a oponerse de manera especial al totalitarismo, pero a ignorar otras formas de desgarramiento que provienen de desigualdades materiales.

\section{BIBLIOGRAFÍA}

Bataillon, G. (2019). Claude Lefort, pensador de lo político. Nueva Sociedad, (281), 152-163. Disponible en: https://nuso.org/articulo/claude-lefort-pensador-delo-politico/

Bhabha, H. K., (2013). Nuevas minorías, nuevos derechos: Notas sobre los cosmopolitismos vernáculos. Buenos Aires: Siglo XXI.

Cheresky, I. (1992). La emergencia de los derechos humanos y el retroceso de lo político. Punto de Vista. Año XV, No. 43. pp. 42-48.

Flynn, B. (2005). The philosophy of Claude Lefort: Interpreting the political. Evanston, III: Northwestern University Press.

Giddens, A. (1997). Consecuencias de la modernidad. Madrid: Alianza.

Gómez, J. M. (1986). Derechos humanos, política y autoritarismo en el Cono Sur. En W. Ansaldi, (comp.). La Ética de la democracia: Los derechos humanos como límite frente a la arbitrariedad. Buenos Aires: Consejo Latinoamericano de Ciencias Sociales.

Hilb, C. (2018). Nuestros años Lefort. Notas sobre la recepción de Claude Lefort en la argentina de la transición a la democracia. Cadernos de Ética e Filosofia Política, $1(32), 140-150$.

Lefort, C. (1986). The Political Forms of Modern Society: Bureaucracy, Democracy, Totalitarianism. MIT Press.

- (1988). Democracy and political theory. Minneapolis: University of Minnesota Press.

— (1990). La invención democrática. Buenos Aires: Nueva Visión.

- (2004). La incertidumbre democrática: Ensayos sobre lo político. Barcelona: Anthropos.

— (2007). El arte de escribir y lo político. Barcelona: Herder.

- (2018). La disolución de las referencias de certeza y la cuestión democrática. En L. Svampa (comp.), ¿Qué hay de política en la filosofía? Ocho ensayos, Buenos Aires: Instituto de Investigaciones Gino Germani, UBA.

Marchart, O. (2009). El pensamiento político posfundacional: La diferencia política en Nancy, Lefort, Badiou y Laclau. México: FCE. 
Moyn, S. (2013). Claude Lefort, Political Anthropology, and Symbolic Division. En C. Lefort: Thinker of the Political, edited, Martín Plot (ed.). Nueva York: Palgrave Macmillan.

Plot, M. (2013). Claude Lefort: Thinker of the political. Basingstoke: Palgrave Macmillan.

Stavrakakis, Y. (2007). Lacan y lo político. Buenos Aires: Prometeo Libros.

Taylor, C. (2006). Imaginarios sociales modernos. Barcelona: Paidós.

Wellmer, A. (2013). Líneas de fuga de la modernidad. Buenos Aires: Fondo de Cultura Económica. 